\title{
Primary tracheal tumours: 21 years of experience at Peking Union Medical College, Beijing, China
}

\author{
L Zhenguaiang, T Pingzhang, Z Dechao*, G Reddy-Kolanu†, V Ilankovan†
}

\begin{abstract}
Objectives: To review our experience of the treatment of primary tracheal tumours.

Study design: All medical notes of patients with primary tracheal tumours diagnosed between 1981 and 2002 were retrospectively analysed.

Results: In this period, 80 patients were diagnosed with primary tracheal malignancy, 48 males and 32 females. The median age was 48 years. Sixty-nine patients had malignant tumours, most commonly adenoid cystic carcinoma (50.7 per cent) or squamous cell carcinoma (30.4 per cent). Fifty-five patients underwent surgery, 30 of whom also received radiotherapy. Twenty-five patients received only radiotherapy. The five-year survival rate for all malignant tumours was 30.5 per cent. The five-year survival rates for adenoid cystic carcinoma and squamous cell carcinoma were 40.2 and 24.6 per cent, respectively. Local recurrence and distant metastases developed in 21 patients (30.4 per cent).

Conclusion: Primary tracheal tumours are rare and mainly malignant. Surgery is the most effective treatment method. Technical advances allow for safe resection of the tumour with a safe, tension-free anastomosis.
\end{abstract}

Key words: Trachea Neoplasms; Squamous Carcinoma; Surgery; Radiotherapy

\section{Introduction}

Primary tracheal tumours are rare, with an incidence in the order of one in a million. ${ }^{1}$ Over 80 per cent of these tumours are malignant. The predominant histological types are adenoid cystic carcinoma (40 per cent) and squamous cell carcinoma (SCC) (36 per cent). ${ }^{2}$

Most patients have a history of smoking (77.3 per cent), particularly those with SCC (93.3 per cent). ${ }^{3}$ The most common presenting symptom is dyspnoea, followed by haemoptysis and cough $;^{3-5}$ haemoptysis is more common in cases of SCC and dyspnoea more common in adenoid cystic carcinoma. ${ }^{6}$ In the absence of haemoptysis, a diagnosis of adult-onset asthma is often made, thus delaying definitive treatment. The mean duration of symptoms prior to diagnosis has been shown to be four months in general and 12 months for adenoid cystic carcinoma. 5

Tracheal cancer comprises adenoid cystic carcinoma in 25.7-40 per cent of cases and SCC in 25.7-45.2 per cent of cases. ${ }^{2,3,5}$ The remaining histological types are varied and include squamous papilloma, carcinoid tumours, mucoepidermoid tumours, and a variety of carcinomas and sarcomas. ${ }^{7}$

Three treatment modalities have been applied to tracheal tumours: tracheal resection, endoscopic resection and radiotherapy. Where possible, resection with or without radiotherapy has been suggested to be the best modality for long-term survival. $3,5,6,8$ Furthermore, post-operative radiotherapy has been suggested to increase survival only in incompletely resected tumours. ${ }^{5}$

The likelihood of survival has been shown to be improved in cases with complete resection. ${ }^{5,6}$ Gaissert et al. ${ }^{6}$ found mean survival rates of 38 months in resected SCC cases and 8.8 months in unresectable SCC cases. For adenoid cystic carcinoma cases, the mean survival rates were 69 months for resected cases and 41 months for unresectable cases. Positive lymph nodes were associated with a worse prognosis in SCC cases; however, there was no such association in adenoid cystic carcinoma cases.

We present one of the largest series of primary tracheal cancer yet published, with the aim of sharing our experience of these rare but potentially treatable tumours.

\section{Materials and methods}

Patients

The medical records of all patients with primary tracheal tumours diagnosed between January 1981 
and December 2002 were evaluated. This included all patients with benign and malignant primary tumours located between the cricoid cartilage and the tracheal bifurcation.

The study group comprised 80 patients, 48 male and 32 female. The median age was 48 years (range 16-75). Almost all the patients were symptomatic. The commonest symptoms were dyspnoea (68.8 per cent), cough (53.8 per cent), hoarseness (13.8 per cent) and 'asthma' (11.3 per cent). The median course from onset of symptoms to diagnosis of the tumour was 20 months (range 0-64 months). Thirty-two patients (40 per cent) had an initial misdiagnosis, of bronchitis $(n=22)$, asthma $(n=6)$, thyroid tumour $(n=2)$, oesophageal cancer $(n=1)$ or cardiac disease $(n=1)$.

Sixty-nine (86 per cent) of the patients had malignant tumours. These comprised 35 cases of adenoid cystic carcinomas (44 per cent) and 21 cases of SCC (26 per cent). Eleven patients (14 per cent) had benign tumours, the most common type being pleomorphic adenoma (5 per cent), followed by haemangioma (3 per cent). The distribution of histopathological types for the primary tracheal tumours is shown in Table I.

All patients were examined with chest roentgenography and fibre-optic bronchoscopy or nasopharyngolaryngoscopy. Some patients also had lateral neck radiographs, computed tomograms or magnetic

TABLE I

PRIMARY TRACHEAL TUMOURS: HISTOPATHOLOGICAL TYPES

\begin{tabular}{|c|c|c|c|c|}
\hline \multirow[t]{2}{*}{ Histopathology } & \multicolumn{3}{|c|}{ Site } & \multirow[t]{2}{*}{ Total } \\
\hline & Cervical & Mid & Carina & \\
\hline Malignant & & & & 69 \\
\hline Adenoid cystic carcinoma & & & & 35 \\
\hline $\begin{array}{l}\text { - Unknown differentiation } \\
\text { (tubular \& cribriform) }\end{array}$ & 17 & 14 & 2 & \\
\hline - Poor differentiation (solid) & 2 & - & - & \\
\hline $\mathrm{SCC}$ & & & & 21 \\
\hline - Unknown differentiation & 2 & 6 & 1 & \\
\hline - Well differentiated & 1 & - & - & \\
\hline - Moderate differentiation & 4 & 1 & 1 & \\
\hline - Poor differentiation & 3 & 2 & - & \\
\hline Mucoepidermoid carcinoma & & & & 5 \\
\hline - Unknown differentiation & - & 2 & 1 & \\
\hline - Moderate differentiation & - & 2 & - & \\
\hline Non-Hodgkin's lymphoma & 2 & & & 2 \\
\hline $\begin{array}{l}\text { Carcinoma, poor } \\
\text { differentiation }\end{array}$ & 1 & 1 & - & 2 \\
\hline Small cell carcinoma & 1 & 1 & - & 2 \\
\hline $\begin{array}{l}\text { Adenocarcinoma, moderate } \\
\text { differentiation }\end{array}$ & 1 & - & - & 1 \\
\hline Adenosquamous carcinoma & - & 1 & - & 1 \\
\hline Benign & & & & 11 \\
\hline Pleomorphic ademoma & 2 & 2 & - & 4 \\
\hline Haemangioma & 1 & 1 & - & 2 \\
\hline Hamartoma & - & 1 & - & 1 \\
\hline Lipoma & - & 1 & - & 1 \\
\hline Schwannoma & 1 & - & - & 1 \\
\hline Neurofibroma & - & 1 & - & 1 \\
\hline Papilloma & - & - & 1 & 1 \\
\hline Total & 38 & 36 & 6 & 80 \\
\hline
\end{tabular}

Data represent case numbers. $\mathrm{SCC}=$ squamous cell carcinoma resonance imaging. In most patients, biopsy was performed at endoscopy before therapy. The tumours were located in the cervical region in 38 cases, in the mid-trachea in 19 cases, in the low trachea in 17 cases and in the carina in six cases. Fifty-five patients (68.8 per cent) underwent surgical resection.

\section{Treatment}

Of the 38 patients with cervical tracheal tumours (Figure 1), 12 had no resection but did receive radiotherapy. Of these, four patients also had a tracheostomy. Twenty-six patients underwent segmental tracheal or partial tracheal wall and tumour resection. Of these, 16 received post-operative radiotherapy.

Segmental tracheal resection with end-to-end anastomosis was performed in 11 cervical tumour patients. Of these, a cervical collar incision was used in five patients, with or without thyroid lobectomy and recurrent laryngeal nerve dissection. A combined cervico-mediastinal incision with a partial or complete sternotomy ( $\mathrm{T}$ incision) was used in six patients, with or without laryngeal and hilar release.

Partial tracheal wall resection was performed in 13 cervical tumour patients. Of these, a cervical collar incision was used in 11 patients, with or without thyroid lobectomy and recurrent laryngeal nerve dissection. A combined cervico-mediastinal incision with partial or complete sternotomy was used in two patients. Tracheal reconstruction was performed in six patients, a sternocleidomastoid myoperiosteal flap being used in five patients and a skin graft in one patient. Two patients underwent total laryngeal and partial tracheal resection with thyroid lobectomy.

Of the 36 patients with primary thoraco-tracheal (mid and low trachea) tumours (Figure 2), 11 received only radiotherapy and 25 underwent segmental or partial tracheal and tumour resection. Of the 25 surgical patients, 11 had post-operative radiotherapy and one had pre-operative radiotherapy.

Segmental resection with an end-to-end anastomosis was performed in 17 thoraco-tracheal tumour patients. Of these, a right posterolateral thoracotomy was used in 14 patients, with or without laryngeal or hilar release, and a complete sternotomy was used in three patients.

A partial tracheal, carina, and right and left main bronchus resection with carinal reconstruction was performed in two thoraco-tracheal tumour patients via a right posterolateral thoracotomy. A simple partial tracheal and tumour resection with direct tracheal closure were performed in six patients via a right posterolateral thoracotomy.

Of the six patients with carinal tumours (Figure 3 ), two had only radiotherapy and four had surgery. A partial tracheal, carina, and left and right main bronchus resection with carinal reconstruction were performed in three patients via a right posterolateral thoracotomy. One patient had a partial tracheal and carinal resection with left pneumonectomy and carinal reconstruction via a right posterolateral 


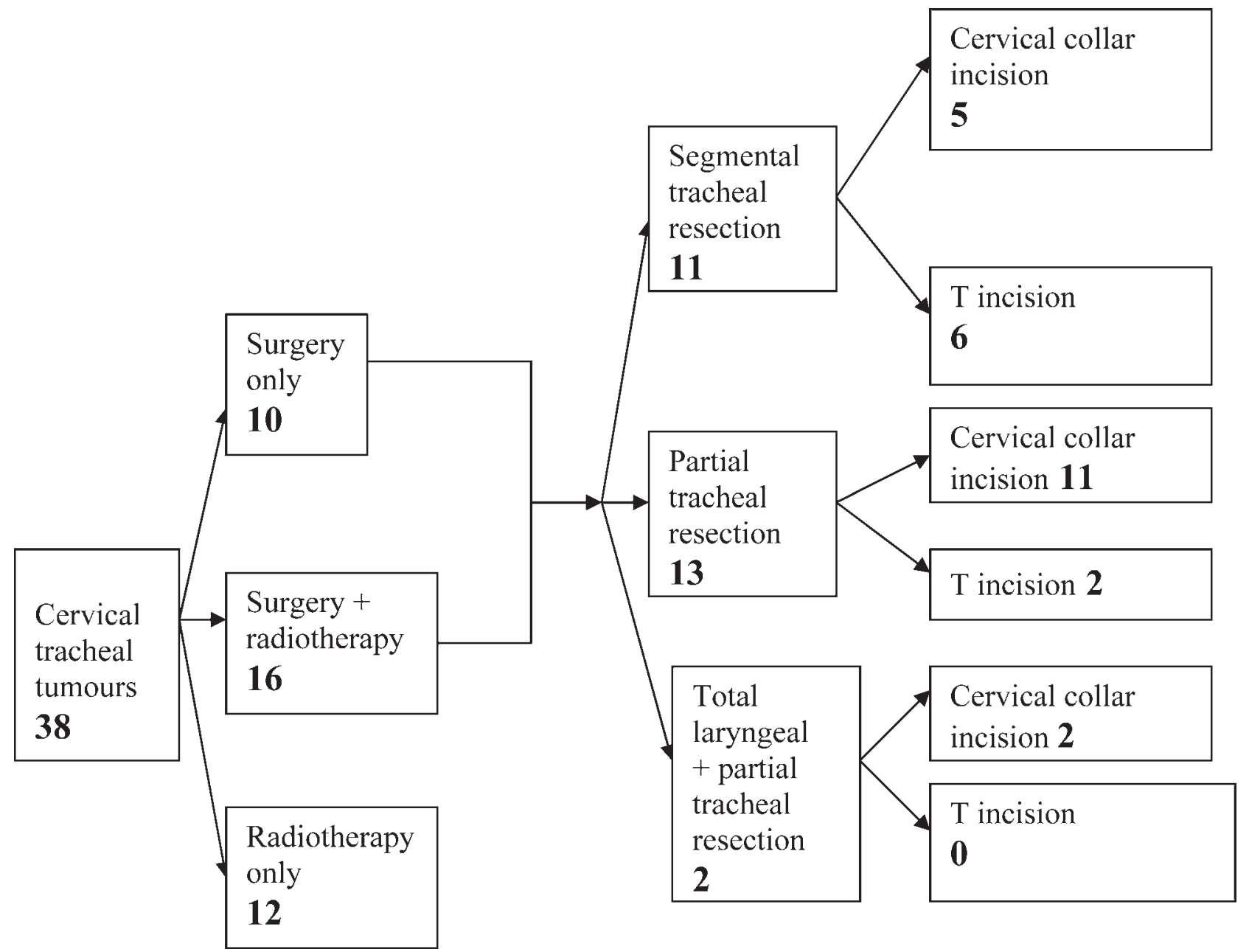

FIG. 1

Management of cervical tracheal tumours.

thoracotomy. One patient had post-operative radiotherapy and one had pre-operative radiotherapy.

\section{Results}

\section{Treatment modalities}

Of the 35 patients with adenoid cystic carcinoma, surgery was performed in 28 , post-operative radiotherapy was given to 17 and pre-operative radiotherapy to one. Seven patients received only radiotherapy as they refused surgery.

In the 21 patients with SCC, surgery was performed in 10 patients, and six of these also received post-operative radiotherapy. The remaining 11 patients received only radiotherapy. The treatment of patients with other malignancies is detailed in Table II.

\section{Complications}

Three patients died as a result of treatment: one suffered post-operative respiratory failure, one died of post-operative bleeding and one died of radiotherapy complications.

Ten patients suffered post-therapeutic complications. Tracheal stenosis occurred in five patients, four of whom had received post-operative radiotherapy; all these patients had cervical tumours. Of the five patients with tracheal stenosis, two underwent segmental resection, one underwent partial tracheal resection with a sternocleidomastoid myoperiosteal flap reconstruction, one underwent a posterior tracheal wall resection with skin graft and one underwent a simple tracheal resection. Wound infection developed in two patients, followed in one case by tracheal stenosis. Postoperative hoarseness developed in two patients, and a tracheoesophageal fistula developed in one patient after radiotherapy.

\section{Oncological results}

The surgical margin was positive in 17 patients (14 with adenoid cystic carcinoma and three with SCC), all of whom received post-operative radiotherapy (external beam and/or endoluminal brachytherapy).

All patients were followed up in clinic postoperatively. Five patients were lost to follow up. In the follow-up period, 25 patients died. Of these, three died due to the treatment (as detailed above), seven died of local recurrence, one died of local recurrence with distant metastases, seven died of 


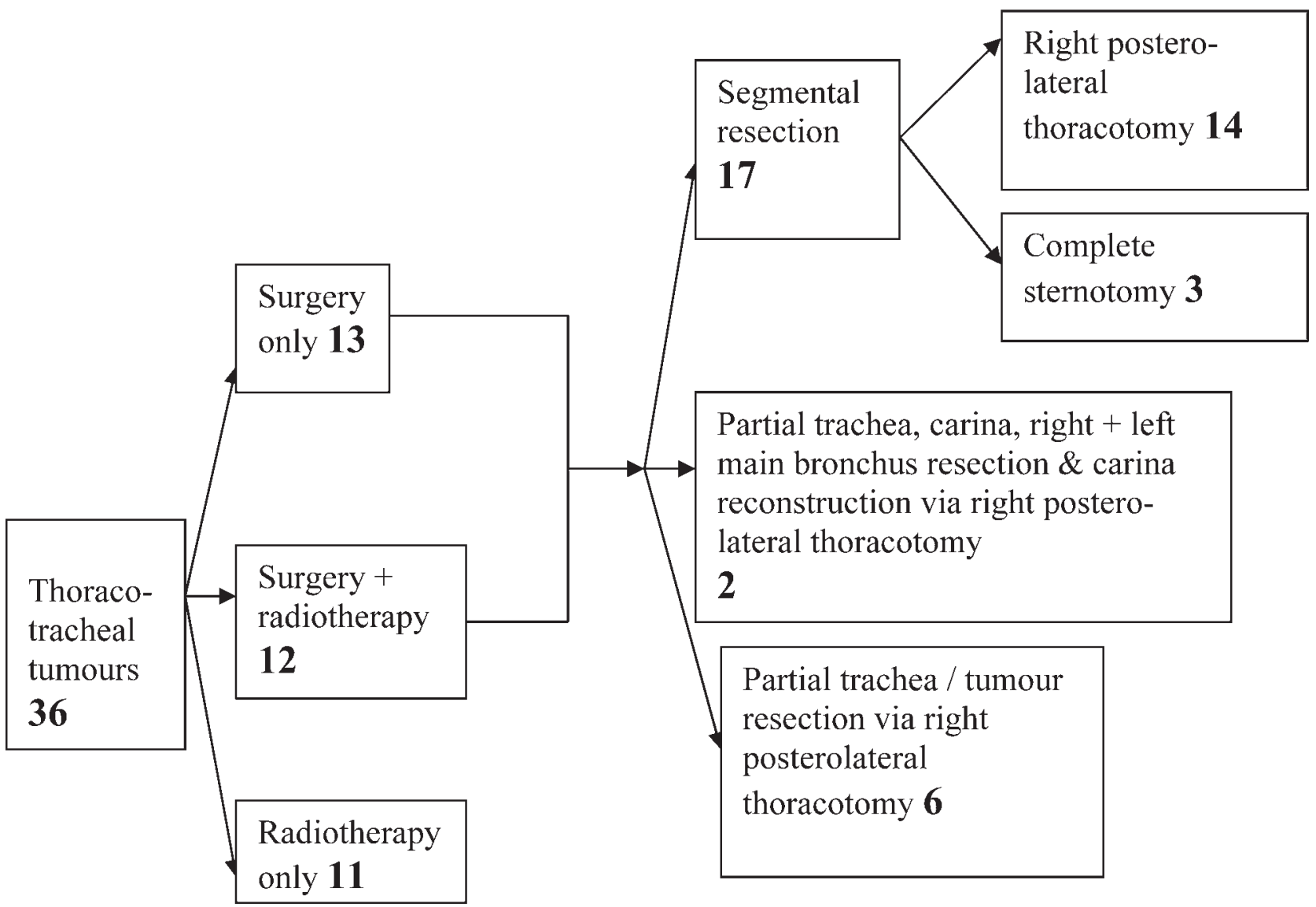

FIG. 2

Management of thoraco-tracheal tumours.

distant metastases, three died of synchronous primary tumours and four died of other diseases. The five-year survival rate for all tumours was 30.5 per cent, being 40.2 per cent for adenoid cystic carcinoma and 24.6 per cent for SCC.

Overall, local recurrence and/or distant metastases developed in 21 patients. Local recurrence occurred in eight patients, pulmonary metastases in six, local recurrence with pulmonary metastases in two, pulmonary and bone metastases in one, pulmonary and liver metastases in one, and bone metastases in three.

Of the 35 patients with adenoid cystic carcinoma, local recurrence occurred in six, local recurrence with pulmonary metastases in two, pulmonary metastases in three, pulmonary and bone metastases in one, pulmonary and liver metastases in one, and bone metastases in three. The local recurrence rate was 23 per cent and the distant metastases rate was 23 per cent, with the most common distant metastasis site being the lung (seven of eight).

Of the 21 patients with SCC, none developed local recurrence. Pulmonary metastases developed in two patients and bone metastases in one.

No recurrence occurred in any of the patients with benign tumours.

A second primary carcinoma was found in 10 patients: seven had lung cancer, one had lung and laryngeal cancer, one had oesophageal cancer, and one had tracheal cancer.

\section{Discussion}

In our 21 years of experience within a major cancer centre, only 80 patients have been diagnosed with primary cancer of the trachea. As found in previous studies, ${ }^{2,3,5}$ the majority of these tumours were malignant, with adenoid cystic carcinoma and SCC dominating. There were a greater number of cases in men (48/80); however, other contributing factors such as smoking were not examined.

The predominant symptoms were respiratory. As found in previous studies, there were a significant number of misdiagnoses (40 per cent), mostly of other respiratory diseases (88 per cent). The length of time between onset of symptoms and diagnosis is of concern, with a median time of 20 months, compared with a mean duration of four to 12 months in a French study. ${ }^{5}$ The delay in presentation may explain the 40 per cent five-year survival rate in our series, compared with 60-70 per cent reported in the literature. This may be improved by increased use of out-patient flexible bronchoscopy, enabling visualisation of the lesion and, if necessary, prompt biopsy under general anaesthesia. 


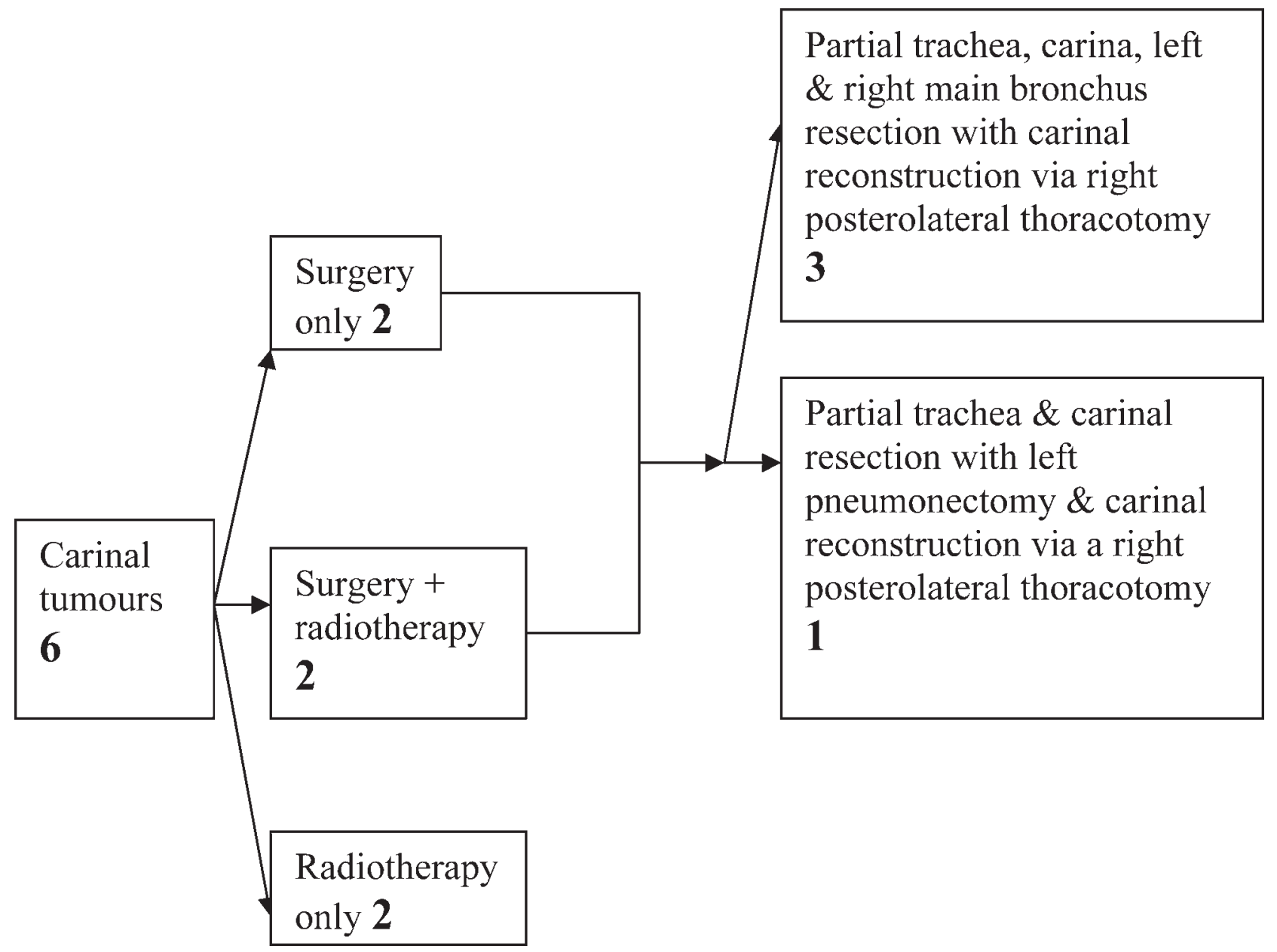

FIG. 3

Management of carinal tracheal tumours.

The majority of patients were treated surgically (68.8 per cent); this treatment modality has been suggested to be best for long-term survival. $3,5,6,8$ One patient with non-Hodgkin's lymphoma underwent primary radiotherapy, as he had been wrongly diagnosed at biopsy as having SCC.

In order for the tumour resection to be viable, the resultant anastomosis must not be under tension. Tension may be eased by blunt dissection anterior and posterior to the trachea, and laryngeal and hilar release can be performed if necessary. In our experience, 4.5 to $5.0 \mathrm{~cm}$ of the trachea can reliably be resected, enabling end-to-end anastomosis with acceptable tension.

A variety of approaches are required to gain access to disease at different sites in the trachea. A collar incision with the neck in hyperextension delivers nearly half the trachea above the sternal notch and, after blunt dissection, the carina is easily palpable. Malignant cervical and upper thoracic lesions, and nearly all benign lesions, can be removed in this way. The addition of a sternotomy enables further exposure. Tumours of the distal trachea and carina require a right posterolateral thoracotomy or a complete sternotomy.

In our series, 28 ( 80 per cent) adenoid cystic carcinoma patients and 10 (48 per cent) SCC patients underwent surgery. The greatest length of trachea resected was $6.0 \mathrm{~cm}$. Of the 38 patients with cervical primary tracheal tumours, five were repaired with a sternocleidomastoid myoperiosteal flap; tracheal stenosis developed in only one of these patients, suggesting that this was a reliable mode of repair. Nonresectability was due to locoregional disease, excessive length of disease or distant metastases.

Of the 55 patients who underwent surgery, two died as a result of post-operative complications (bleeding and respiratory failure) and 10 had manageable complications. Seventeen patients (31 per cent) had disease at the surgical margins; this compares favourably to the 49 per cent with positive surgical margins reported by Harvard Medical School. ${ }^{6}$ Of those patients with positive margins, 14 had adenoid cystic carcinoma and three had SCC. This result is not unexpected, as adenoid cystic carcinoma is known to spread along perineural spaces or lymphatics within the trachea, so surgical margins are frequently positive well away from the grossly apparent tumour. This finding also serves to emphasise the difficulty of performing a complete resection without compromising the integrity of the procedure. Grillo et al. reported that microscopic tumour at the resection margins does not impair anastomotic healing 
TABLE II

PRIMARY TRACHEAL TUMOURS: THERAPEUTIC MODALITIES

\begin{tabular}{|c|c|c|c|c|}
\hline Histopathology & Surgery & $\begin{array}{l}\text { Pre-op } \\
\text { RT }\end{array}$ & $\begin{array}{l}\text { Post-op } \\
\text { RT }\end{array}$ & $\begin{array}{l}\text { RT } \\
\text { only }\end{array}$ \\
\hline $\begin{array}{l}\text { Adenoid cystic carcinoma } \\
\text { - Unknown } \\
\text { differentiation (tubular } \\
\text { \& cribriform) }\end{array}$ & 26 & 1 & 17 & 7 \\
\hline $\begin{array}{l}\text { - Poor differentiation } \\
\text { (solid) }\end{array}$ & 2 & - & 2 & - \\
\hline $\begin{array}{l}\text { SCC } \\
\text { - Unknown } \\
\text { differentiation }\end{array}$ & 1 & - & - & 8 \\
\hline - Well differentiated & 1 & - & 1 & 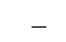 \\
\hline 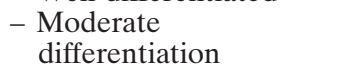 & 5 & - & 3 & . \\
\hline $\begin{array}{l}\text { - Poor differentiation } \\
\text { Mucoepidermoid } \\
\text { carcinoma }\end{array}$ & 3 & - & 2 & 2 \\
\hline $\begin{array}{l}\text { - Unknown } \\
\text { differentiation }\end{array}$ & 2 & 1 & 1 & 1 \\
\hline 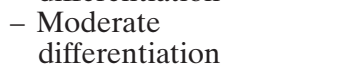 & 2 & - & - & - \\
\hline $\begin{array}{l}\text { Non-Hodgkin's } \\
\text { lymphoma }\end{array}$ & 1 & - & 1 & 1 \\
\hline $\begin{array}{l}\text { Carcinoma, poor } \\
\text { differentiation }\end{array}$ & - & - & - & 2 \\
\hline Small cell carcinoma & - & - & - & 2 \\
\hline $\begin{array}{l}\text { Adenocarcinoma, } \\
\text { moderate } \\
\text { differentiation }\end{array}$ & 1 & - & - & - \\
\hline $\begin{array}{l}\text { Adenosquamous } \\
\text { carcinoma }\end{array}$ & - & - & - & 1 \\
\hline
\end{tabular}

Data represent case numbers. Pre-op $=$ pre-operative; $\mathrm{RT}=$ radiotherapy; post-op $=$ post-operative; $\mathrm{SCC}=$ squamous cell carcinoma

and does not preclude long term survival, especially in cases of adenoid cystic carcinoma. ${ }^{2}$

- Primary tracheal tumours are rare and mainly malignant

- This paper reviews the treatment of primary tracheal tumours in 80 Chinese patients

- A number of technical advances have been made to enable a tension-free anastomosis after adequate resection

- Due to the difficulty of ensuring microscopic clearance, the use of adjuvant radiotherapy should be considered in most cases

- In the future, with earlier diagnosis, a greater number of such tumours will hopefully be amenable to surgical resection, thus maximising treatment potential

Reported five-year survival rates for primary tracheal cancer are very variable. A French study ${ }^{5}$ found five-year survival rates of 73 per cent for adenoid cystic carcinoma and 47 per cent for SCC, while a recent Texan study found a five-year diseasespecific mortality rate of 72.9 per cent. ${ }^{3}$ In this latter study, the five-year survival rate for all malignant tumours was 30.5 per cent, and the five-year survival rates for adenoid cystic carcinoma and SCC were 40.2 and 24.6 per cent, respectively. These findings are towards the lower end of the reported spectrum of results, which may be due to the fact that some patients only received radiotherapy, and the 'lost to follow up' patients were considered to be dead.

The majority of the literature on primary tracheal cancer has come from institutions in the West. We presume that the patient cohorts involved were mainly Caucasian. The current study represents the only reported findings for an entirely Chinese cohort. We are not certain whether ethnicity plays a role in the behaviour of primary tracheal tumours, as reflected in altered five-year survival rates, but it is an interesting question.

\section{References}

1 Manninen MP, Antila PJ, Pukander JS, Karma PH. Occurrence of tracheal carcinoma in Finland. Acta Otolaryngol 1991;111:1162-9

2 Grillo HC, Mathisen DJ. Primary tracheal tumors: treatment and results. Ann Thorac Surg 1990;49:69-77

3 Webb BD, Walsh GL, Roberts DB, Sturgis EM. Primary tracheal malignant neoplasms: the University of Texas MD Anderson Cancer Center experience. J Am Coll Surg 2006;202:237-46

4 Thotathil ZS, Agarwal JP, Shrivastava SK, Dinshaw KA. Primary malignant tumours of the trachea - the Tata Memorial Hospital experience. Med Princ Pract 2004;13:69-73

5 Regnard JF, Fourquier P, Levasseur P. Results and prognostic factors in resections of primary tracheal tumours: a multicenter retrospective study. J Thorac Cardiovasc Surg 1996; 111: $808-13$

6 Gaissert HA, Grillo HC, Shadmehr MB, Wright CD, Gokhale M, Wain JC et al. Long-term survival after resection of primary adenoid cystic and squamous cell carcinoma of the trachea and carina. Ann Thoracic Surg 2004;78: 1889-96

7 Gaissert HA, Grillo HC, Shadmehr MB, Wright CD, Gokhale M, Wain JC et al. Uncommon primary tracheal tumours. Ann Thorac Surg 2006:82:268-72

8 Kurien G, Cole I. Primary carcinoma of the trachea. Clin Otolaryngol Allied Sci 1981;6:197-204

Address for correspondence:

Dr V Ilankovan,

Consultant,

Oral, Maxillofacial and Head \& Neck Surgery,

Department of Head \& Neck Surgery,

Poole Hospitals NHS Trust,

Longfleet Road

Poole BH15 2JB, UK.

Fax: 01202442005

E-mail: velupillai.ilankovan@poole.nhs.uk

Dr V Ilankovan takes responsibility for the integrity of the content of the paper.

Competing interests: None declared 